\title{
TRANSFERS OF CELL SODIUM AND POTASSIUM IN EXPERIMENTAL AND CLINICAL CONDITIONS ${ }^{1}$
}

\author{
By J. R. ELKINTON, A. W. WINKLER,2 AND T. S. DANOWSKI \\ (From the Department of Internal Medicine, Yale University School of Medicine, New Haven; \\ Department of Research Medicine, University of Pittsburgh School of Medicine
}

(Received for publication August 29, 1947)

In recent years much interest has been manifested in transfers of cellular electrolytes in various disease states. Loss of the main cation, potassium, in "excess" of nitrogen has been found in fasting (1), diarrhea (2), diabetic coma $(3,4)$, and dehydration (5). It has further been shown that at least partial replacement of deficits of cell potassium by increments of extracellular sodium occurs in animals on low potassium-high sodium diets $(6,7)$, in animals treated with desoxycorticosterone $(8)$, in subjects with alkalosis $(9,10)$ and in some infants with diarrhea (11). Furthermore, the administration of potassium as well as sodium and water has been found to be therapeutically advantageous in some of these conditions $(4,12)$.

Not only do extensive transfers of electrolytes across the cell boundaries take place, but alterations in osmotic activity of the constituents of the cells occur as well (13 to 15$)$. Presumably this is due to changes in the degree of dissociation of the cations bound with protein, phosphates, or other organic complexes. The conditions governing such phenomena and their relation to transfers of cations across the cell membrane are not known.

In this paper data are analyzed from a large number of experiments in dogs and human subjects with various alterations of body water and electrolytes. It is our purpose to identify factors which condition transfers of cations, to seek relationships between sodium and potassium during movements into and out of cells, and to calculate the osmotic adjustments which accompany such exchanges.

\section{EXPERIMENTAL MATERIAL}

Animal studies. The experimental data used in these analyses have been reported previously in a series of papers (16 to 20). Body fluids were altered as follows:

\footnotetext{
1 Aided by grants from the Fluid Research Fund of Yale University.

2 Deceased, June 26, 1947.
}

(1) hypertonicity and an increased concentration of sodium in body fluids were produced by either (a) injection of 2 to 6 per cent sodium chloride solution or (b) dehydration of the subject by means of urea diuresis or prolonged water deprivation; (2) hypotonicity and a lowered concentration of sodium were produced by either (a) intraperitoneal injection and subsequent withdrawal of glucose solution or $(b)$ infusion of glucose solution into nephrectomized animals.

Reverse movements of body water were subsequently induced in 3 of these 4 groups. This was accomplished by giving water to dehydrated subjects (group $1 b$ above), or sodium chloride to those with a deficit of sodium or an. excess of water (groups $2 a$ and $2 b$ above). By these procedures the volume of intracellular water, which was decreased in the hypertonic animals and increased in those with hypotonicity, was restored partially or completely to normal.

Human studies. Data presented elsewhere (21) on subjects with or without food while on a partially or totally restricted intake of fluid are analyzed in this paper for evidences of transfers and inactivation of body base. In addition, data are used from experiments involving alterations in body water and electrolytes derived from 2 patients with attacks of periodic paralysis treated with potassium chloride (22); from another with congestive failure and anasarca; and a fourth with cirrhosis and ascites. These are used together with the experimental findings in 2 normal subjects (23). One of these took 240 grams of carbohydrate together with 20 grams of potassium chloride, and the other took large volumes of physiological saline during intervals of 4 and 6 hours, respectively.

The experimental procedures and the chemical methods have already been described $(5,15,16)$.

Calculation of changes in cellular sodium and potassium. On the assumption that the chloride in extracellular fluid is not increased or decreased by movements of this ion out of or into cells, the change in cellular sodium ( $\left.\mathrm{Na}_{1}^{\prime}\right)$ or potassium $\left(\mathrm{K}_{\mathrm{I}}^{\prime}\right)$ which has taken place in "excess" of protein or nitrogen may be calculated as follows :

$$
\begin{aligned}
& \Delta \mathrm{NaI}^{\prime}=\mathrm{b}_{\mathrm{N}_{\mathbf{E}}}-\Delta \mathrm{Na}_{\mathrm{I}}-\Delta \mathrm{Na}_{\mathrm{P}} \\
& \Delta \mathrm{K}_{\mathbf{I}}^{\prime}=\mathrm{b}_{\mathrm{K}}-\Delta \mathrm{K}_{\mathrm{E}}-\Delta \mathrm{K}_{\mathrm{P}}
\end{aligned}
$$

where

$b_{N_{a}}$ and $b_{x}=$ balances of $\mathrm{Na}$ and $K$.

$\Delta \mathrm{Na}$ and $\Delta \mathrm{K}_{\mathrm{m}}=$ changes in $\mathrm{Na}$ and $\mathrm{K}$ in the extracellular fluid (E), as measured by the chloride space. 
$\Delta \mathrm{Na}$ and $\Delta K_{P}=$ changes in cellular $\mathrm{Na}$ and $\mathrm{K}$ associated with the catabolism or anabolism of protein. These are calculated on the basis that each kilogram of waterfree muscle protein in the normal dog contains 7 m.eq. of sodium and 380 m.eq. of potassium $(5,16)$. These values are only slightly different in human muscle.

Calculation of changes in osmotically active cell base. The osmotically active cell base is taken to be that portion of sodium and potassium in cells which is not bound to other cellular constituents, such as the proteins and the phosphate complexes. This portion is, therefore, ionized and exerts an osmotic force. Variations in its magnitude induce movements into and out of cells in response to osmotic forces. ${ }^{3}$

The change in the amount of osmotically active base is taken to be the difference between the predicted balance of base $\left(b_{B}\right)$ and the observed balances of sodium and potassium $\left(b_{\mathrm{Na}+\mathrm{K}}\right)$. The former is calculated :

where

$$
b_{B}=W_{2} B_{2}-W_{1} B_{1}
$$

$B_{1}$ and $B_{2}=$ initial and final concentration of base in the body fluids.

$W_{1}$ and $W_{2}=$ initial and final volume of total body water.

The predicted base balance rests on the change in body water and the assumption of complete osmotic equilibrium, and has no relation to the chloride space.

\section{RESULTS}

\section{Transfers of potassium}

It is apparent from Figure 1 that in dogs and humans under a variety of experimental conditions which alter greatly the water and electrolytes in the various body fluid compartments, potassium left cells far more often than it entered.

Cellular potassium decreased in a wide variety of experimental conditions, none of which appeared to be an indispensable prerequisite to such a change. These decrements were observed most often, however, in hypertonicity and dehydration produced by water restriction or urea diuresis (small solid circles, Figure 1). The potassium in cells declined significantly-i.e., more than $10 \mathrm{~m}$.eq. in dogs and more than 25 m.eq. in humans-in 26 out of 44 experiments of this type. Hypertonicity induced by the injection of sodium chloride solutions, on the other hand, was associated

3 This refers to the end result, and does not exclude the possibility that the process is initiated by alterations in the osmotic activity or the base-binding capacity of cellular anions. with a loss of cell potassium in only 6 out of 19 studies (large closed circles). Hypotonicity resulting either from salt depletion or injection of water into animals without renal function (open circles, small and large, respectively) was accompanied by a decrease in cellular potassium in only 9 out of 37 periods.

It is to be noted, furthermore, that these decreases in the cell potassium occurred without comparable increases of potassium in the extracellular fluid. The dog with anoxemia in this series (half-closed circle, Figure 1) with a large rise in serum potassium exactly equivalent to the drop in cell potassium is an exception to the general observation. This animal, however, was in an agonal state, and ordinary physiological forces and processes were no longer operative. In general, therefore, potassium which left cells merely passed through the extracellular fluid to be excreted.

However, when some profound interference with the renal mechanism, circulatory or anatomical, was present, potassium did not leave the cells. No such serious impairment of renal function developed in any of the human studies. In some of the animals, however, oliguria or anuria was produced by salt depletion and circulatory collapse, ureteral ligation, or bilateral nephrectomy (symbols with bars superimposed). In these, potassium remained in the cells. Hence, the ability or inability to excrete extracellular potassium is one factor which conditions movement of this cation out of cells.

On the other hand, entry of potassium into cells, in so far as it could be detected by the techniques employed in this study, appears to depend upon the availability of an exogenous supply of the cation. Without such a supply potassium entered cells in only 1 of the experiments recorded on Figure 1. Even this instance is questionable, however, since the amount, 30 m.eq., falls just outside the error inherent in the human experimental procedure. In sharp contrast to this finding, large amounts (100 to 200 m.eq.) entered the cells of each of the 3 patients given potassium (solid squares, Figure 1).

\section{Transfers of sodium}

In Figure 2 it can readily be seen that the wide variety of experimental procedures employed 


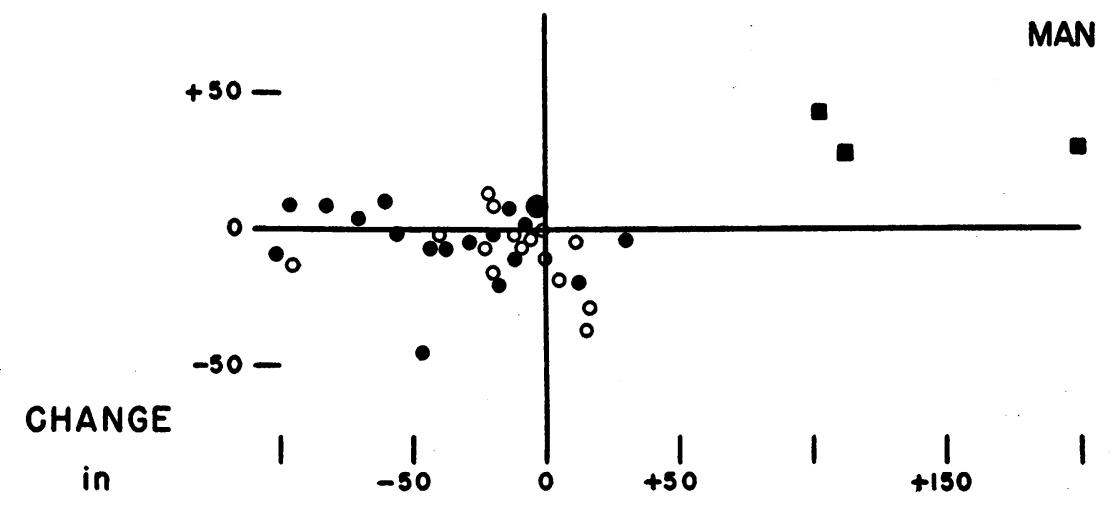

\section{EXTRA-}

CELLULAR

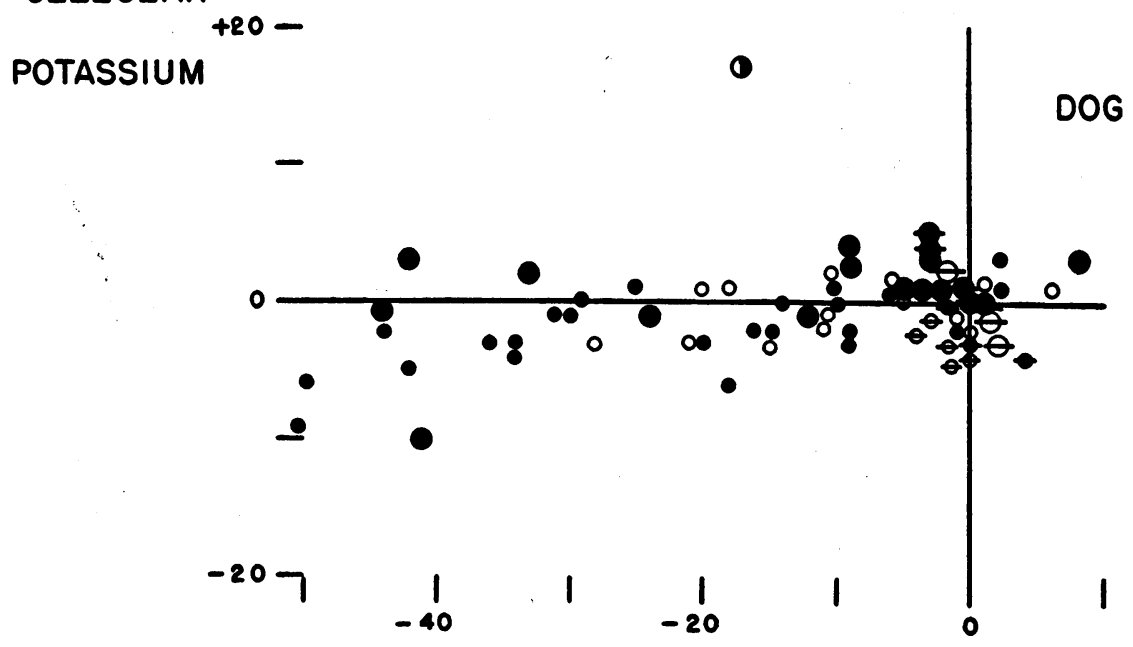

CHANGE in

CELL POTASSIUM

m.eq.

Fig. 1. Relation Changes in Extracellular Potassium to Changes in Intracellular Potassium

Closed circles indicate experiments in which hypertonicity of body fluids was produced by the administration of hypertonic saline solutions (large closed circles), or by dehydration (small closed circles). Open circles represent studies in which body fluids became hypotonic as a result of the infusion of glucose solution into animals without renal function (large open circles), or as a result of salt depletion (small open circles). Superimposed bar on symbol identifies animals with oliguria or anuria. Closed squares represent patients given potassium. The half-closed circle indicates an animal in the agonal state.

tended to increase cell sodium, whereas under similar circumstances, as already seen in Figure 1, potassium usually declined. These cations differ in other respects as well. First, extensive increases of intracellular sodium did occur solely at the expense of extracellular sodium and inde- pendently of an exogenous supply of the cation. Hypertonicity was the most frequent correlate of such a movement. Second, sodium left cells to enter the extracellular fluid in oliguric or in nephrectomized animals (symbols with superimposed bar). These observations contrast sharply 


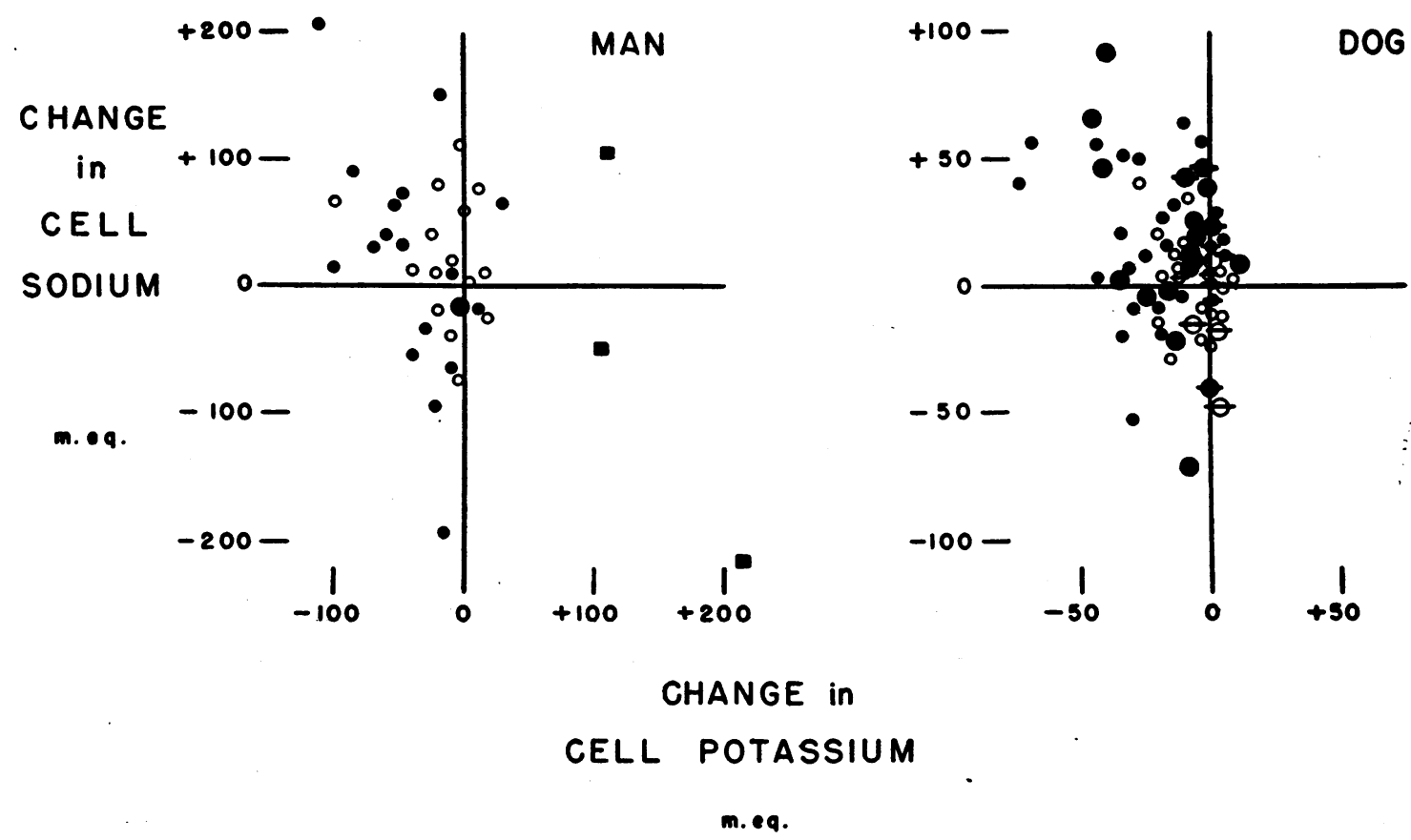

Fig. 2. Relation of Transfers of Cellular Sodium to Those of Cellular Potassium Symbols are the same as in Figure 1.

with the behavior of potassium analyzed in the preceding section.

\section{Relation of cell potassium to cell sodium transfers}

There is evident no consistent quantitative reciprocal relationship between transfers of cell sodium and cell potassium (Figure 2 ). It can only be said that in a majority of the periods, and in 2 of the 3 cases in which potassium chloride was administered, the balance of cell potassium was negative and that of cell sodium was positive.

This was especially true in the dehydration experiments (small solid circles). The addition of sodium in excess of water (large solid circles) resulted in either a positive or negative balance of cell sodium, and only some of the positive balances were associated with losses of cell potassium. It is significant, however, that many animals in this category with increases in cell sodium without losses of cell potassium were anuric because of nephrectomy, ureteral ligation or salt depletion shock (symbols with superimposed bar). In these, therefore, the failure to observe reciprocal decreases or increases in potassium could be related to the limitations imposed on potassium transfers in the absence of adequate renal function.

In the group of subjects who developed negative balances of cellular sodium, concomitant positive balances of cellular potassium, with but 2 exceptions (solid squares), were conspicuous by their absence. In those 2 experiments exogenous potassium was available. In the others it was not.

\section{The relation of the net exchanges of cell cations to changes in osmotic activity (Figure 3)}

There is a rough inverse correlation between the net exchanges of cell sodium and potassium and the internal alterations in osmotically active cell base, in that these 2 changes had the opposite signs in a majority of the periods. There was no quantitative relationship in most of the periods, however, and in many the changes were in the same direction. No one set of experimental conditions showed an increased correlation.

Experiments in which distortions of body water and electrolytes were partially or fully corrected sometimes showed reversal of these 2 values. In a total of 36 such periods, the net exchange of cell sodium plus potassium was reversed in 18 , and 
the balance change in osmotically active cell "base" was reversed in 20 .

\section{DISCUSSION}

Certain generalizations concerning transfers of sodium and potassium are now permissible. It appears, for example, that large movements of potassium into cells can occur, provided that an exogenous supply of the cation is available. This has been observed in 1 patient given large amounts of carbohydrate as well as potassium chloride, and in 2 others who received potassium chloride in treatment of an attack of familial periodic paralysis. Apparently a similar penetration of exogenous potassium into cells can occur in the treatment of infant diarrhea and diabetic acidosis $(4,11)$. In these conditions, however, previous losses of potassium are being replaced. This may have been true in the 2 patients above with periodic paralysis. Such was definitely not the case in the patient given carbohydrate and potassium chloride.

It is not possible to state from data on hand whether an increase in the amount of potassium in an organism can per se lead to transfers of this ion into the cells. From in vitro blood cell studies it would appear that even a large concentration gradient in serum is not a sufficient impetus for the entry of potassium into cells, if metabolic processes are held in abeyance (24). Transfers of lesser magnitude are known to occur in association with metabolic activities without an exogenous supply of potassium. This has been observed in vitro during glycolysis in defibrinated blood, and in the pre-paralytic phase of periodic paralysis $(8,22,25)$. Whether or not such small exchanges occurred in the in vivo experiments analyzed in this paper cannot be determined because they would fall in the range of the cumulative error of the analyses and calculations.

Movements of potassium out of cells, on the other hand, are, in part at least, dependent on adequate excretion of potassium. Cellular dehydration has been found to be the one disturbance most consistently conducive to the migration of potassium out of cells. However, in the absence of effective kidney function potassium during life does not leave its cellular position in any significant quantity, irrespective of any changes which may have been induced.

This dependency of potassium transfers out of and into cells on an adequate renal function in the former instance, and on an exogenous supply of cation in the latter, contrasts sharply with the behavior of sodium which is subject to neither of these restrictions.

It is probable that reciprocal exchanges of these cations are modified by these restrictions which are imposed upon potassium transfers. As an inevitable corollary to these non-reciprocal movements of these 2 cations adjustment in behalf of osmotic forces must occur. This is accomplished in one or both of 2 ways. Water may traverse the cell membrane, or base in the cell may be inactivated or reactivated from the osmotic point of view.

Possible sources of error in the calculations which permit the above conclusions should be pointed out. The transfers of cell sodium and cell potassium are calculated on the assumption that the chloride in extracellular fluid does not enter cells and that chloride present in cells does not move out into the extracellular fluid. Obviously such transfers of chloride between cells and serum would affect the estimation of changes in extracellular volume from changes in the chloride space. If, for example, chloride did come out of the cells, false low values for the extracellular volume would be obtained. Conversely, if chloride entered cells, the extracellular volumes would be erroneously high. These deviations from actuality would in turn affect the estimation of sodium exchanges in particular, and to a minor and probably insignificant extent, those of potassium. It is possible, therefore, that in some of the experiments in Figures 1, 2, and 3 apparent transfers of sodium may merely represent unrecognized changes in the chloride space. It seems unlikely, however, that such transfers of chloride, if they did occur, could imperil the validity of the conclusions in this paper. First, it has been shown that measurements of extracellular volume by mannitol correlate closely with values obtained from alterations in the chloride space (22). Second, generalizations in this paper have been drawn only from experiments with changes in sodium and potassium definitely outside the possible sources of error, including those inherent in the use of the chloride space in calculating changes in extracellular water. Third, even though errors resulting from chloride transfers were present, they would, in general, merely 

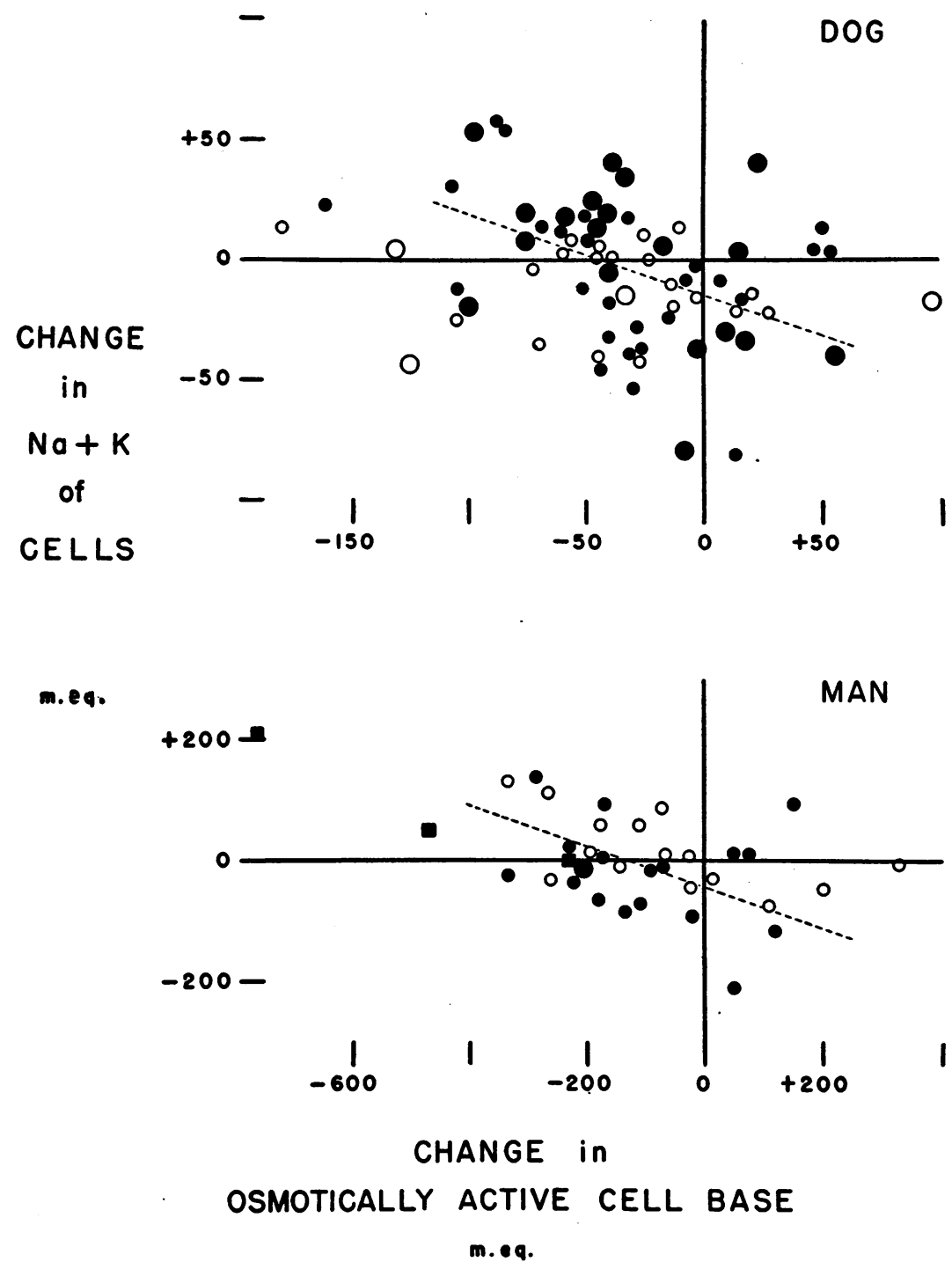

Fig. 3. Relation of the Sum of the Transfers of Cellular Sodium and Potassium to Changes in Osmotically Active Cell Base

Symbols are the same as in Figure 1.

alter the degree rather than the direction of the transfers of cations. Finally, in any particular experiment, errors in calculating changes in extracellular volume would be common to both the sodium and potassium calculations. Hence the relations of these 2 transfers to each other would remain essentially unchanged. Actually, the chief error in the calculation of these transfers lies in the determination of serum sodium because the fraction in cells is such a small portion of the amount of sodium in the body.

Alterations in the chloride space do not enter into the calculation of changes in osmotically active cell base. The sources of error in this calculation have been critically analyzed in an earlier paper (15). Concentration gradients between various compartments of the body fluids, for example, would invalidate some of the derived data. The duration of the experiments makes such gradients unlikely. Moreover, in many of the experiments the gradient would have to be opposite in direction to that expected from the conditions of the experiment, to account for the change in osmotically active base. Furthermore, even if an error of 4 
m.eq. per liter $( \pm 2)$ is allowed in the concentration of the serum sodium, it would not explain the discrepancies. The calculations of at least some of the larger changes in osmotically active base, therefore, are not invalidated by the above major sources of error.

The findings in these experiments permit discussion of certain ideas dealing with the distribution of cations between extracellular fluid and cells. Boyle and Conway (26) have propounded a theory which seemed to them to meet thermodynamic requirements; namely, that the muscle cell membrane is impermeable to extracellular sodium and intracellular anions (phosphate and protein). Therefore, potassium must be intracellular and chloride and bicarbonate extracellular. If a small amount of chloride and bicarbonate were intracellular, an equivalent amount of potassium would be extracellular. On this model increments or decrements of potassium would be distributed through both phases in proportion to the volume of water in each phase. The theory fails, however, to explain the exchange of sodium for potassium in the cell and it ignores the relation of transfers of $\mathrm{K}$ to oxidative reactions (25). Figure 1 clearly indicates that potassium is not added to or subtracted from the 2 phases of body fluid in proportion to their relative volumes, as the theory of Boyle and Conway would require. The ratio of the increments or decrements of cell potassium to those of extracellular potassium was frequently of much greater magnitude than that of the ratio of intracellular to extracellular volume. In other words considerable amounts of cell potassium were transferred across the extracellular phase with very little change in potassium content of the latter. Other mechanisms than isotonic distribution of potassium between the 2 phases must be responsible. Furthermore, the lack of a close relationship between transfers of cell sodium and cell potassium suggests at least semi-independent control of each ion. In Figure 2 it is seen that there is no strictly quantitative reciprocal relation between the two in a great majority of the experiments. These findings are consistent with the data of Darrow (11) which demonstrated inverse balances of cell sodium in only half of the cases of infant diarrhea with depletion of cell potassium. The evidence does not support the concept that cellular sodium is merely a substitute for missing cell potassium. The data presented in this paper support the theory that cation exchanges across the cell boundary are related to metabolic activities of the cell and the expenditure of energy, rather than to passive transfers resulting from differential impermeabilities.

The factors which alter the osmotic activity of the cellular components cannot be defined from the experiments at hand. The most striking fact about these alterations is their magnitude. As indicated earlier the balance of osmotically active cell base greatly exceeds that of the net exchanges of sodium and potassium across the cell boundary. This fact suggests that this reaction may sometimes be primary, and not secondary to the net transfers of cations into or out of the cells. Certainly from the standpoint of shifts of water, a change in the osmotic activity of cell components is often the most important determinant of the ultimate distribution of water between the phases of body fluid. The most striking example of this fact is present in $\operatorname{dog} 115(20)$ in which at 2.7 hours all of the 1.1 liter of water given as 5 per cent glucose solution was retained in the extracellular phase plus an additional 0.1 liter transferred from the intracellular phase. Short of a very large and unlikely water gradient persisting between the 2 phases, this peculiar distribution of water can only be explained by the inactivation of a large amount of cell base, or by a complete failure of glucose to diffuse across the cell membrane. Similarly in prolonged water deprivation, the amount of water released from the intracellular phase by the inactivation of base greatly exceeds that removed by net transfers of cations out of the cell, by breakdown of protein, and by osmotic shifts (16). Whether or not such inactivation, or reactivation, serves a useful purpose is not known.

\section{SUMMARY AND CONCLUSIONS}

1. Potassium leaves cells in significant amounts only if it can be excreted. Hypertonicity and cellular dehydration are frequent, though not invariable, correlates of such movements.

2. Transfers of large amounts of potassium into cells have been observed only when exogenous potassium was available.

3. Sodium, unlike potassium, can enter the serum from cells even though renal function is greatly impaired or ceases entirely. 
4. In contrast to potassium large increases in cell sodium are not dependent upon the exogenous supply of this cation.

5. Exchanges of sodium for potassium in cells do occur. This is not, however, an invariable finding in any particular experimental procedure, nor are the transfers, when present, always of equivalent magnitude.

6. Alterations in the osmotic activity of cations of cells are not correlated closely with either the direction or the magnitude of the transfers of sodium or of potassium.

7. The implications of these data with respect to the theories concerning the distribution of cations between cells and extracellular fluid are discussed.

\section{BIBLIOGRAPHY}

1. Benedict, F. G., A study of prolonged fasting. Carnegie Institution, Publication No. 203, Washington, D. C., 1915.

2. Butler, A. M., McKhann, C. F., and Gamble, J. L., Intracellular fluid loss in diarrheal disease. $\mathrm{J}$. Pediat., 1933, 3, 84.

3. Atchley, D. W., Loeb, R. F., Richards, D. W., Jr., Benedict, E. M., and Driscoll, M. E., On diabetic acidosis; a detailed study of electrolyte balances following the withdrawal and reestablishment of insulin therapy. J. Clin. Invest., 1933, 12, 297.

4. Butler, A. M., Talbot, N. B., Burnett, C. H., Stanbury, J. B., and MacLachlan, E. A., Metabolic studies in diabetic coma. Trans. Assoc. Am. Physicians, 1947, in press.

5. Elkinton, J. R., and Winkler, A. W., Transfers of intracellular potassium in experimental dehydration. J. Clin. Invest., 1944, 23, 93.

6. Heppel, L. A., The electrolytes of muscle and liver in potassium-depleted rats. Am. J. Physiol., 1939, $127,385$.

7. Miller, H. C., and Darrow, D. C., Relation of muscle electrolyte to alterations in serum potassium and to the toxic effects of injected potassium chloride. Am. J. Physiol., 1940, 130, 747.

8. Ferrebee, J. N., Parker, D., Carnes, W. H., Gerity, M. K., Atchley, D. W., and Loeb, R. F., Certain effects of desoxycorticosterone; the development of "diabetes insipidus" and the replacement of muscle potassium by sodium in normal dogs. Am. J. Physiol., 1941, 135, 230.

9. Gamble, J. L., Fahey, K. R., Appleton, J. E., and MacLachlan, E. A., Congenital alkalosis with diarrhea. J. Pediat., 1945, 26, 509.

10. Darrow, D. C., Congenital alkalosis with diarrhea. J. Pediat., 1945, 26, 532.
11. Darrow, D. C., The retention of electrolyte during recovery from severe dehydration due to diarrhea. J. Pediat., 1946, 28, 515.

12. Govan, C. D., Jr., and Darrow, D. C., The use of potassium chloride in the treatment of the dehydration of diarrhea in infants. J. Pediat., 1946, 28, 541 .

13. Yannet, H., and Darrow, D. C., The effect of depletion of extracellular electrolytes on the chemical composition of skeletal muscle, liver, and cardiac muscle. J. Biol. Chem., 1940, 134, 721.

14. Mellors, R. C., Muntwyler, E., and Mautz, F. R., Electrolyte and water exchange between skeletal - muscle and plasma in the dog following acute and prolonged extracellular electrolyte loss. J. Biol. Chem., 1942, 144, 773.

15. Elkinton, J. R., Winkler, A. W., and Danowski, T. S., Inactive cell base and the measurement of changes in cell water. Yale J. Biol. \& Med., 1944, 17, 383.

16. Elkinton, J. R., and Taffel, M., Prolonged water deprivation in the dog. J. Clin. Invest., 1942, 21, 787.

17. Winkler, A. W., Elkinton, J. R., Hopper, J., Jr., and Hoff, H. E., Experimental hypertonicity: alterations in the distribution of body water and the cause of death. J. Clin. Invest., 1944, 23, 103.

18. Hopper, J., Jr., Elkinton, J. R., and Winkler, A. W., Plasma volume of dogs in dehydration, with and without salt loss. J. Clin. Invest., 1944, 23, 111.

19. Danowski, T. S., Elkinton, J. R., and Winkler, A. W., The deleterious effect in dogs of a dry protein ration. J. Clin. Invest., 1944, 23, 816.

20. Elkinton, J. R., Winkler, A. W., and Danowski, T. S., The importance of volume and of tonicity in salt depletion shock. J. Clin. Invest., 1947, 26, 1002.

21. Winkler, A. W., Danowski, T. S., Elkinton, J. R., and Peters, J. P., Electrolyte and fluid studies during water deprivation and starvation in human subjects, and the effect of ingestion of fish, of carbohydrate, and of salt solutions. J. Clin. Invest., 1944, 23, 807.

22. Danowski, T. S., Elkinton, J. R., Burrows, B. A., and Winkler, A. W., Exchanges of sodium and potassium in familial periodic paralysis. J. Clin. Invest., 1948, 27, 65.

23. Elkinton, J. R., and Danowski, T. S., Unpublished data.

24. Hald, P. M., Tulin, M., Danowski, T. S., Lavietes, P. H., and Peters, J. P., The distribution of sodium and potassium in oxygenated human blood and their effects upon the movements of water between cells and plasma. Am. J. Physiol., 1947, 149, 340.

25. Danowski, T. S., The transfer of potassium across the human blood cell membrane. J. Biol. Chem., 1941, 139, 693.

26. Boyle, P. J., and Conway, E. J., Potassium accumulation in muscle and associated changes. J. Physiol., $1941,100,1$. 